OPEN ACCESS

Edited by:

Rebecca Elizabeth Tharme,

Riverfutures Ltd, United Kingdom

Reviewed by:

Nitin Kaushal,

World Wide Fund for Nature, India

Robert Alexander Speed,

Badu Advisory Pty Ltd, Australia

Jamie Pittock,

Australian National University, Australia

John Campbell Conallin,

Charles Sturt University, Australia

*Correspondence:

Jackie M. King

jackie.king@watermatters.co.za

Specialty section:

This article was submitted to

Freshwater Science,

a section of the journal

Frontiers in Environmental Science

Received: 20 December 2017

Accepted: 14 September 2018

Published: 24 October 2018

Citation:

King JM and Brown C (2018) Environmental Flow Assessments Are Not Realizing Their Potential as an Aid to Basin Planning.

Front. Environ. Sci. 6:113 doi: 10.3389/fenvs.2018.00113

\section{Environmental Flow Assessments Are Not Realizing Their Potential as an Aid to Basin Planning}

\author{
Jackie M. King ${ }^{1,2 *}$ and Cate Brown ${ }^{1,3}$ \\ ${ }^{1}$ Institute for Water Studies, University of the Western Cape, Cape Town, South Africa, ${ }^{2}$ Water Matters, Cape Town, \\ South Africa, ${ }^{3}$ Southern Waters Ecological Research and Consulting, Cape Town, South Africa
}

Multiple planned dams in developing countries, mostly for hydropower, are threatening some of the world's great river systems. Concern over their social and environmental impacts has led to hydropower being excluded from the sustainability term 'green energy.' Better planning, design and operation of hydropower dams could guide where to build and not to build, and how to mitigate some of their negative impacts. Impact assessments presently done for dams include Cumulative Impact Assessments (CIAs) or similar at the basin level, and Environmental Impact Assessments at the project level. These typically do not detail how the river ecosystem could change and the implications for its dependent social structures. A comprehensive Environmental Flows (EFlows) Assessment does provide this information but is almost always not linked to the other impact assessments. When done at all, it is often rudimentary; rarely basin-wide; and almost always done after major development decisions have already been made. A more effective approach for any basin targeted for hydropower or other large dam development would be to formally and automatically embed the requirement for a basin-wide, detailed EFlows Assessment into a CIA. This should be done at the earliest stage of planning, before dam sites are selected and allocated to developers. The EFlows method adopted matters, as it dictates the scope and flexibility of a study. Rapid one-size-fits-all methods do not provide the detail that governments and other stakeholders need to understand the possible future of their river basins, negotiate and make informed decisions.

Keywords: river degradation, EFlows, basin-wide, hydropower, Cumulative Impact Assessments

\section{BACKGROUND}

The global demand for energy is driving an unprecedented surge in dam building to generate hydropower (Zarfl et al., 2015). Much of this construction is in areas relatively untouched by development until the last decade or so, targeting natural areas and river systems that supply water, food and lifestyle support to hundreds of millions of people. The scale of new or planned large dams is immense: more than 300 in the Mekong Basin of which 176 are for hydropower (http://www. cgiar.org); 60 in the Brazilian Amazon and 200 in the Northeast Indian Himalayas (https://www. internationalrivers.org). Southern Africa's largest river, the Zambezi, already has four hydropower projects (HPPs) producing $5 \mathrm{GW}$ of installed hydropower, with a further $130 \mathrm{GW}$ of potential identified (Beilfuss, 2012). China plans $120 \mathrm{GW}$ of new hydropower from the Salween, Mekong, Yangtze and Brahmaputra Basins. 
It is widely recognized that dams offer numerous benefits to humanity, but the scale of hydropower construction now planned or underway will adversely affect the diversity and resilience of whole river systems, crossing national boundaries with substantial knock-on effects into politics and human conflict (Zarfl et al., 2015; King and Brown, 2018). Concerns over the social and environmental impacts of HPPs (US EPA, 1989; Abell, 1994; Vörösmarty et al., 2010; Pierce-Smith, 2012) are such that hydropower has been excluded from the sustainability term 'green energy' (Maurer et al., 2011; Gibson et al., 2017). The growing negative image of hydropower seems to stem from a common, intractable business-as-usual view that fails to engage meaningfully with the importance of the full range of values and uses of river ecosystems. There is an apparent widespread-not necessarily universal-inertia to embracing new thinking in largescale water planning. As governments, international funders and River Basin Organizations commit themselves to more caring and equitable development, their adherence to these principles is far from assured. Sustainable development of water resources is at greater risk than ever before. A new wave of river degradation is underway and hydropower is becoming firmly linked to this.

We believe that hydropower has a potentially valuable role to play in some national economies, and that better planning, design and operation of HPPs could help mitigate some of their negative impacts. This would have to include, from the earliest stage of planning, formal inclusion of detailed information on the ecological functioning, ecosystem services and social values of targeted river ecosystems, for the full range of stakeholders to consider. In three decades of such work, we have found that comprehensive Environmental Flows (EFlows) Assessments generate a vital portion of the necessary data and understanding for this to happen, providing information that was not available to decision makers until the last decade or so.

\section{EFLOWS ASSESSMENTS}

EFlows Assessments provide information on the links between river flows and river health. In their most comprehensive form, they describe the predicted basin-wide ecological and social outcomes linked to scenarios of different water management options. Where new hydropower is involved, the scenarios can also encompass different permutations of dam numbers, locations, designs, operations and power generation. This provides important insights on dam viability, consequences for ecosystems services and biodiversity, and the trade-offs needed to ensure sustainability. Such information is invaluable in helping guide decisions on whether or not to build, the design of meaningful mitigation measures, the fine-tuning of dam operation and, in some cases, identification and design of biodiversity offsets.

Conventional wisdom is that the level of detail for an EFlows Assessment should increase as the scale of the assessment decreases, so that basin-wide assessments can be done as rapid, low-resolution, low-confidence inputs and project-specific assessments as high-resolution detailed inputs (Richter et al., 1997; Arthington et al., 2003; Acreman and Dunbar, 2004). We have come to believe that this is not necessarily so and, under the scale of HPP and other dam development now underway, the EFlows approach that would most often make sense is one that is basin-wide and highly detailed.

\section{WHY?}

HPPs' impacts on rivers are specific to their design, location and operation, and to the nature of the targeted river. Many HPPs in one basin each contribute an impact, plus an additional layer of group impacts that no single HPP might produce. In multiHPP planning, now all too common for the world's large river basins, we can no longer afford to consider proposed projects in isolation but need in-depth EFlows investigations at an early stage of planning that consider the potential incremental and cumulative impacts over a whole basin from a suite of projects (e.g., NCEA, 2015).

At present, HPP investigations are largely confined to economic and engineering considerations, with perhaps some preliminary low-resolution, broad-scale biodiversity inputs. Governments might provide a list of planned HPP sites with pre-granted environmental licenses (Maurer et al., 2011), but typically the criteria for their selection relate to power generation and the cost of energy. These sites may then be allocated to developers (IFC, 2012). Major decisions on location, design and price of electricity are thus frequently made with at best rudimentary consideration of the social, biodiversity and riverhealth implications for the whole basin. In some cases, a Strategic Environmental Assessment (SEA; NCEA, 2015), Cumulative Impact Assessment (CIA ${ }^{1}$; IFC, 2013) or similar is done to guide decision-making in these basins, but almost always these postdate the major decisions on number and location of HPPs, and are relegated to tinkering with an already-laid plan (Meynell et al., 2014). Further, unless they include a detailed, systematic EFlows Assessment they too run the risk of failing to identify or address key environmental and design challenges related to the river ecosystem and its dependent people.

Developers may thus later be faced with, and could understandably be reluctant to address, issues that had not been spelled out when the project was awarded. These could include a requirement to release EFlows beyond those factored into their bid, to forego peak-power generation, or to meet international funders' safeguards or performance standards, such as "no nett biodiversity loss" (IFC, 2012). At a fairly advanced stage of planning, potential impacts that did not form part of the original decision to invest might surface and need to be addressed through adherence to the mitigation hierarchy of Avoidance, Minimization, Restoration and Offsets (Mitchell, 1997; IFC, 2012), with new implications for the viability of the project. Faced with such potentially deal-breaking uncertainties some

\footnotetext{
${ }^{1}$ The International Finance Corporation (IFC) defines a CIA as "the process of analyzing potential cumulative impacts and risks of proposed developments in the context of the potential effects of other human activities and natural environmental and social external drivers on chosen valued ecosystem components over time, and proposing concrete measures to avoid, reduce or mitigate such ... impacts and risk to the extent possible" (IFC, 2013).
} 
companies are becoming reluctant to participate in auctions (Maurer et al., 2011).

\section{HOW DO DETAILED BASIN-WIDE EFLOWS ASSESSMENTS ADD VALUE?}

An holistic detailed EFlows Assessment uses permutations of potential water-resource developments in scenarios to predict changes in river health, river resources (such as fish and other food items), biodiversity, river-dependent rural lifestyles and other strategic considerations. The predictions are made at a level of detail that stakeholders can relate to. Done at the basin scale, an EFlows Assessment can identify: the incremental and cumulative effects of all proposed projects on the above; thresholds in the degree of environmental and social impacts; the least- and most-sensitive river reaches in a basin; barriers to flow, sediment and biota that would be least or most destructive; which tributaries could best be developed and which conserved with natural flows and fish migrations (sacrificial $\mathrm{v}$ sacrosanct); the configuration, design and operation of dams that would best promote biodiversity and support fish populations; which rivers are most important to rural communities and why; and how much water in what pattern of flows would be required to maintain different parts of the river system at various levels of health. Opportunities and risks not apparent in single-dam studies are revealed and mitigation impossible at the project scale may become possible in the wider context.

From the perspectives of the developers, funders, governments and society it makes sense to have all of this information available, in detail and at a basin level, before the development pathway for the basin is agreed and project sites are chosen and awarded. Because of this, EFlows Assessments are becoming a prominent vehicle through which IWRM manifests, allowing informed stakeholder and biodiversity negotiations before decisions are made. The challenge is ensuring the appropriate investigations are done at the appropriate time.

\section{HOW MUCH DEVELOPMENT IS TOO MUCH?}

From such work, the concept of Development Space (i.e., development potential) has evolved to address concerns over the widespread development-driven degradation of river systems (Figure 1). The concept provides a limit, identified by the stakeholders via EFlows scenarios, beyond which further development should not proceed because of the resulting social and ecological degradation (King and Brown, 2010). Demonstrating a real road to sustainable development, the country/ies involved accept the limits of development that they identify from the scenarios, and can then apportion the Development Space among themselves in an agreed way that could allow slower-developing countries/sectors to still have their share to use as and when they wish. This becomes, in essence, the foundation of the basin development pathway. Multiple such basin studies form the foundation of country, region or globalbased optimization of development and biodiversity protection
(Zarfl et al., 2015). Although the end point of the Development Space could theoretically be shifted to the right over time, its value in terms of sustainability lies in not readily doing that but by rather strategizing to live within its limit.

\section{ADVANTAGES OF THE BASIN-WIDE APPROACH}

The basin-wide EFlows approach reflects the principles of the World Commission on Dams (WCD, 2000) and has the potential to identify win-win situations. Although governments and developers may view such large-scale planning as onerous and individual project developers feel it is outside their scope of operations, it has the potential to produce multiple benefits for them (Opperman and Harrison, 2008).

- Less uncertainty and controversy: the overall basin plan is negotiated and agreed, and thus there is lower risk for individual developers and funders.

- More streamlined project-level review: there is greater certainty during the review process for individual projects because many of the issues will have been identified and addressed at higher levels of planning.

- Less expenditure on assessing impacts: the EFlows Assessment and biodiversity offset studies are river/basin specific rather than project specific, with costs of these studies shared by developers in a basin. Later more limited EFlows Assessments for individual projects would cost less than if they were standalone.

- Fewer operational constraints: a potentially significant portion of the mitigation obligation of an individual project will be accomplished through contribution to basin-/regional-scale mitigation.

- Positive public recognition: the approach should lead to better energy and conservation outcomes, meeting a standard that the public increasingly demands of development.

- Preferential access to funding: the approach advances hydropower as a source of renewable and sustainable energy in the global market, providing access to carbon-offset markets and mechanisms.

\section{WHAT NEEDS TO CHANGE?}

The sequence of phases of new dam projects is Scoping, Pre-feasibility, Feasibility, Construction and Monitoring. The available impact assessment processes are SEAs, which have a broad spatial and sectoral scope and include strategic political, economic and institutional considerations (NCEA, 2015; Bidstrup et al., 2016); CIAs, which are sectoral and, in the case of hydropower, operate at the spatial scale of river basin or sub-basin; and EIAs, which are project focussed (Baxter et al., 2001). EIAs and CIAs are tasked with proposing concrete measures to avoid, reduce or mitigate identified impacts (Mitchell, 1997), while SEAs generally are not. Conservation Assessments (CA) of whole river basins also occur, but tend to not be linked to, or necessarily inform, water-resource development plans. 


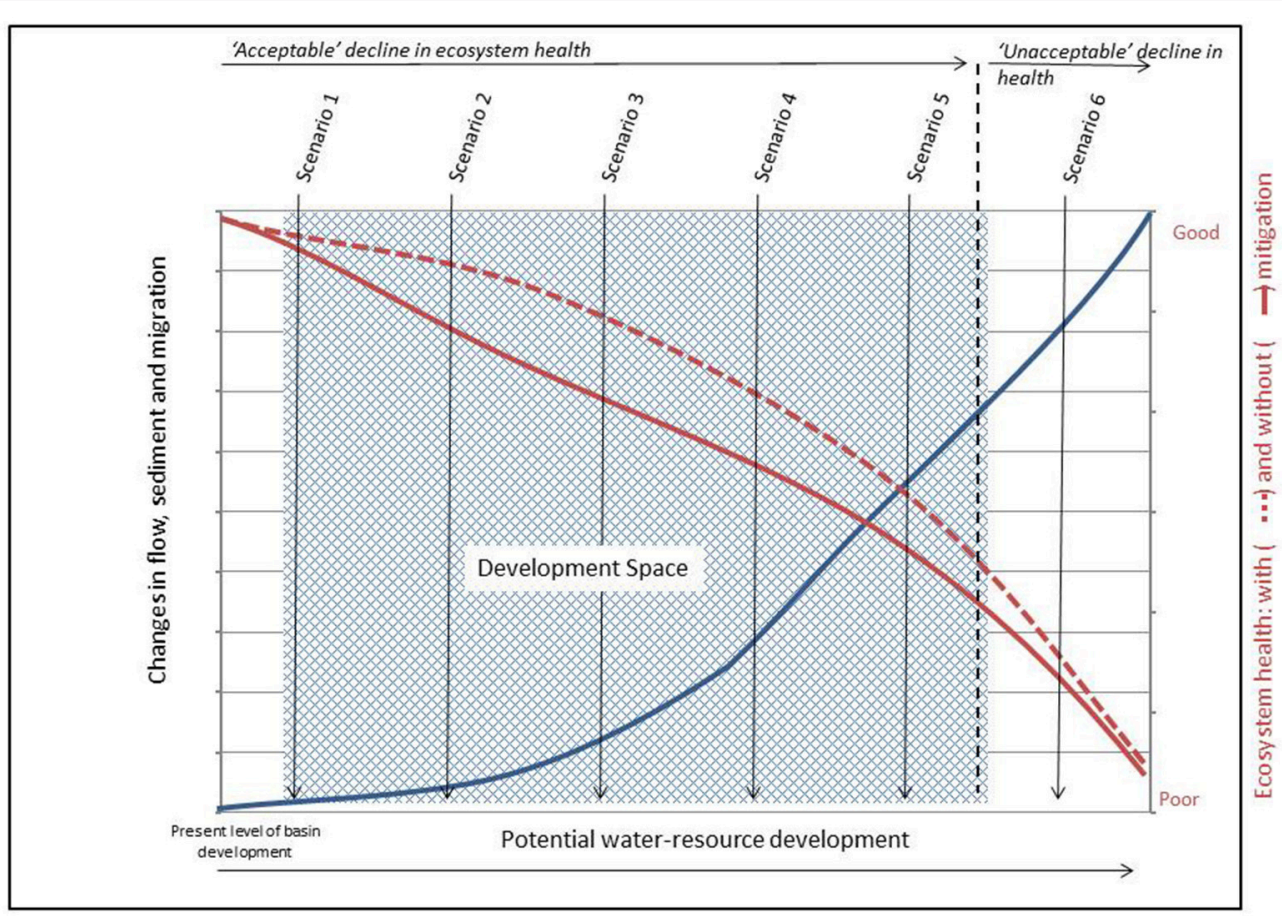

FIGURE 1 | The concept of Development Space, defined by stakeholders after consideration of EFlows scenarios.
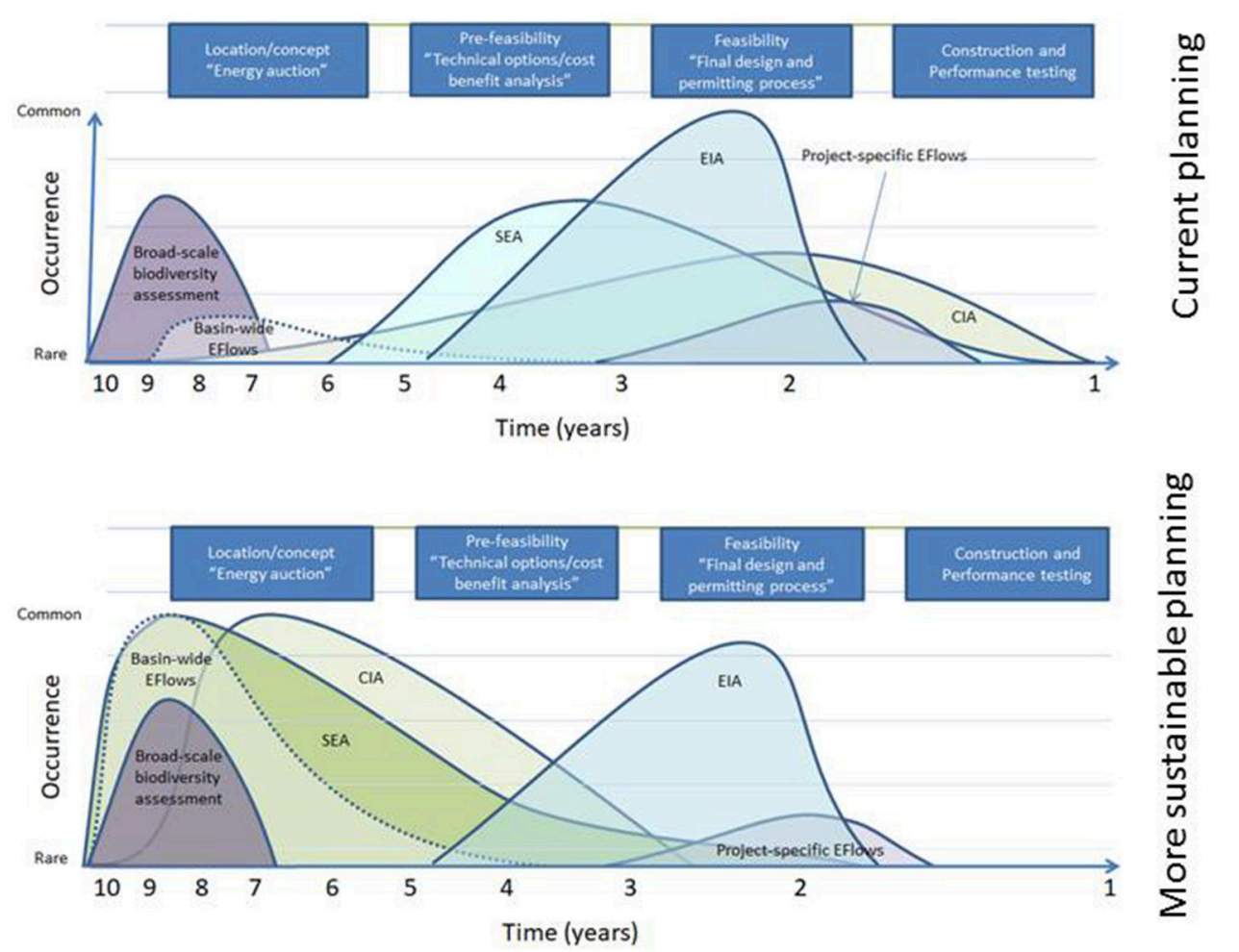

FIGURE 2 | Present and suggested future timing of the various conservation and impact assessments for new dams. 


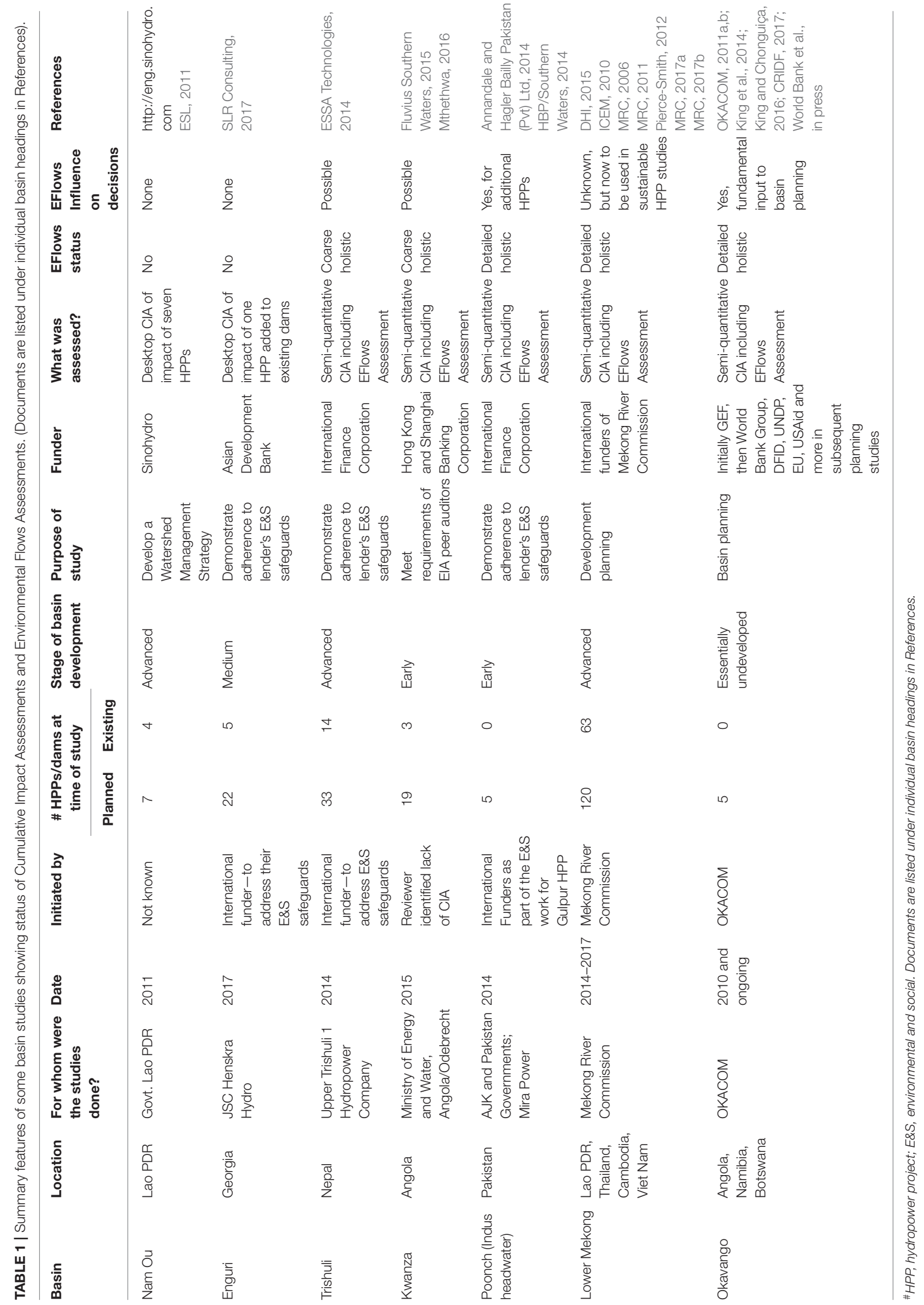


For two decades or more it has been obvious that detailed EFlows Assessments, with their in-depth insights into river functioning, should be automatically embedded into each of the above kind of impact assessments where dams are involved, but almost always they are not. As a result, the substantial changes that can occur to the river ecosystem and its dependent social structures with development are not elucidated. Although some progress has been made in including EFlows work in single-dam projects, basin-wide EFlows Assessments, within or outside the other impact assessments, remain rare. This is at a time when such over-arching perspectives of potential change are more urgently needed than ever before.

A better approach for a basin where multiple HPPs are planned is to synchronize an in-depth, basin-wide EFlows Assessment with a CA, SEA, or CIA as appropriate, at the earliest stages in the planning process (Figure 2). Together they support discussion and negotiation on the desired basin development pathway, the basin Development Space, and what to build and not build. With this completed and decisions made, potential developers would better understand their environmental and social commitments, with the benefits as listed above. Finetuning via an EIA could be done for individual projects as they came online.

\section{EXAMPLES OF BASIN-WIDE APPROACHES}

Basin development is proceeding at such a pace that countries may be planning strategically from a technical perspective, but are not necessarily planning for sustainability. Globally, there is a sequence-mildly chronological but also influenced by who is developing where, funded by whom-from basins where attention to the maintenance of healthy river systems is rudimentary or comes too late, to ones where careful planning precedes any decisions on large-scale development (Table 1).

The CIAs and EFlows Assessments that are done today are most often at the insistence of international lenders. Earlier ones tended to have no or poor guidance on the scope of the CIA and how to include river impacts in a structured way. Many of the assessments have no hope of influencing decisions, and in several cases most if not all dams were already existing or decided upon when they started. Of the examples in Table 1, only the Okavango assessments represent a genuine inclusion of EFlows in the earliest stage of basin planning (King et al., 2014).

The recent partial rectification of this through guidelines on CIAs (e.g., IFC, 2013) and EFlows (e.g., World Bank Group, 2018); the Early Stage Protocol of the International Hydropower Association's Hydropower Sustainability Assessment Protocol (IHA, 2018); and other initiatives (e.g., NCEA, 2015), may lead to increased integration of the discipline of EFlows in planning and impact assessment exercises.

\section{REFERENCES}

Abell, R. (1994). San Juan River Basin Water Quality and Contaminants Review (Alburquerque: University of New Mexico), 78-79.

\section{CONCLUSION}

In basins where widespread water-resource development is taking place, comprehensive basin-wide EFlows Assessments should be a fundamental part of SEAs, CIAs or equivalent (Anantha and Dandekar, 2012; Meynell, 2013; ASTAE, 2014). Together, they should be done at the earliest stage of basin planning, before sites are selected and allocated to developers, in order to provide information on the expected cumulative impacts on the river ecosystem and linked social structures. SEAs and CIAs usually do not provide these insights as the associated EFlows studies are often poor in detail and quality, and produce simple minimum flow recommendations. This situation cannot be well-analyzed because websites may indicate what minimum flow was allocated to the river without providing the documents that led to that decision or stating what the flow was meant to achieve. Minimum flows so recommended do not capture the complex impacts of dams on river ecosystems, and so do not support meaningful engagement with stakeholders on the likely future state of their river. Where a basin-wide EFlows Assessment is done, the method used matters as it dictates the scope and flexibility of a study. Rapid one-size-fits-all methods do not provide the detail that governments and other stakeholders need to negotiate and make informed decisions (ASTAE, 2014; World Bank Group, 2018).

A common impediment to changing the situation of ineffective EFlows studies done at the wrong time (if at all) is the developer's requirement to have been awarded a dam site before investing in relevant basin studies. Developing countries may not have the funds to complete pre-emptive basin-wide environmental and social studies themselves before offering dam sites to bidders, and tend to restrict their analyses mainly to power generation options and the cost of energy. There is growing realization that basin-wide studies in early planning have cascading economic, social and sustainability benefits, as listed above, but the means of doing them independently of the developers and timeously is in its infancy. There is an urgent need for a concerted effort from international funders, governments, EFlows professionals and the international bodies of impact assessors to turn the planning sequence around, and strengthen sustainability planning for countries that may lose more than they gain through careless development.

\section{AUTHOR CONTRIBUTIONS}

The authors listed made an equal direct and intellectual contribution to the work, and approved it for publication.

\section{ACKNOWLEDGMENTS}

We thank the four reviewers, who each added value to this paper.

Acreman, M. C., and Dunbar, M. J. (2004). Methods for defining environmental river flow requirements-a review. Hydrol. Earth Syst. Sci. 8, 861-876.

Anantha, L., and Dandekar, P. (2012). Towards Restoring Flows into the Earth's Arteries: A primer on Environmental Flows. Pune: River Research 
Centre, Kerala \& South Asia Network on Dams Rivers and People. (May 2012). 52.

Annandale, D. D., and Hagler Bailly Pakistan (Pvt) Ltd. (2014). Strategic Environmental Assessment of Hydropower Development in Azad Jammu and Kashmir. Islamabad: IUCN 154.

Arthington, A. H., Rall, J. L., Kennard, M. J., and Pusey, B. J. (2003). Environmental flow requirements of fish in Lesotho rivers using the DRIFT methodology. River Res. Appl. 19, 641-666. doi: 10.1002/rr a.728

Asia Sustainable and Alternative Energy Program (ASTAE) (2014). Cumulative Impacts and Joint Operation of Small-Scale Hydropower Cascades. South Asia Energy Studies. Washington, DC: World Bank.

Baxter, W., Ross, W., and Spaling, H. (2001). Cumulative effects assessment: improving the practice of cumulative effects assessment in Canada. Impact Assess. Project Appraisal 19, 253-262. doi: 10.3152/147154601781 766916

Beilfuss, R. (2012). A Risky Climate for Southern African Hydro: Assessing Hydrological Risks and Consequences for Zambezi River Basin Dams. Berkley: International Rivers, USA. 60.

Bidstrup, M., Kornov, L., and Partidario, M. R. (2016). Cumulative effects in strategic environmental assessment: the influence of plan boundaries. Environ. Impact Assess. Rev. 57, 151-158. doi: 10.1016/j.eiar.2015. 12.003

CRIDF (2017). Climate Resilient Infrastructure Development Facility. Okavango Climate Resilient Development Pathways: PILOT report. UK: DFID. 174.

DHI (2015). Study on the Impacts of Mainstream Dams on the Mekong River. Final Report for Ministry of Natural Resources and Environment, Government of Viet Nam. Project No. 11812032. 94.

ESL (2011). Earth Systems Lao Meteorology, hydrology, sediment transport and water quality baseline and impact assessment of the Nam Ou Hydropower Project. Vientiane, Lao PDR. Report produced for Sinohydro Corporation.

ESSA Technologies (2014). Appendix D: Cumulative Impact Assessment: Upper Trishuli_1 Hydropower project. Prepared for Nepal Water and Energy Development Company and International Finance Corporation. 101.

Fluvius and Southern Waters. (2015). Cuanza River Basin: Assessment of the Cumulative Impacts Associated with Hydropower Development. Unpublished Report. 123.

Gibson, L., Wilman, E., and Laurance, W. (2017). How green is 'green' energy? Trends Ecol. Evol. 32, 922-935. doi: 10.1016/j.tree.2017.09.007

HBP/Southern Waters (2014). Gulpur Hydropower Project. Cumulative Impact Assessment. HBP Ref.: D4BV01GHP. December 2014, 17. http://eng.sinohydro. com

International Centre for Environmental Management (ICEM) (2010). MRC Strategic Environmental Assessment (SEA) of Hydropower on the Mekong Mainstream. Summary of the Final Report. Hanoi, Viet Nam.

International Finance Corporation (IFC) (2012). Performance Standards on Environmental and Social Sustainability. Available online at: www.ifc.org

International Finance Corporation (IFC) (2013). Good Practice Handbook on Cumulative Impact Assessments and Management for the Private Sector in Emerging Markets. Available online at: www.ifc.org

International Hydropower Association (IHA) (2018). Hydropower Sustainability Assessment Protocol. London: IHA, 232.

King, J. M., Beuster, H., Brown, C., and Joubert, A. J. (2014). Pro-active management: the role of environmental flows in transboundary cooperative planning for the Okavango river system. Hydrol. Sci. J. 59, 786-800. doi: $10.1080 / 02626667.2014 .888069$

King, J. M., and Brown, C. A. (2010). Integrated basin flow assessments: concepts and method development in Africa and South-east Asia. Special Issue Freshwater Biol. 55, 127-146. doi: 10.1111/j.1365-2427.2009. 02316.x

King, J. M., and Brown, C. A. (2018). "Environmental Flows, minimum flows and the mystery of ten percent," in From Sea to Source, Protection and Restoring of Fish Migration in Rivers Worldwide, eds K. Brink, P. Gough, P. P. Schollema, and H. Wanningen (Groningen: World Fish Migration Foundation).
King, J. M., and Chonguiça, E. (2016). Integrated management of the Cubango-Okavango River Basin. Ecohydrol. Hydrobiol. 16, 263-271. doi: 10.1016/j.ecohyd.2016.09.005

Maurer, L. T., Barroso, L. A., Chang, J. M., Benoit, P., Fields, D., Flach, B., et al. (2011). Electricity Auctions: An Overview of Efficient Practices. Washington, DC: International Bank for Reconstruction and Development/The World Bank.

Mekong River Commission (MRC) (2006). IBFM Flow Regime Assessment. Integrated Basin Flow Management Report No. 8. Vientiane, Lao PDR. MRC unpublished report. 119.

Mekong River Commission (MRC) (2011). (MRC) Assessment of Basin-wide Development Scenarios and the BDS 2011-2015. Vientiane, Lao PDR.

Mekong River Commission (MRC) (2017a). The Council Study: Study on the Sustainable Management and Development of the Mekong River, Including Impacts of Mainstream Hydropower Projects. BioRA Final Technical Report Series. Volume 4: Assessment of Planned Development Scenarios. Final Report. Vientiane, Lao PDR. 145.

Mekong River Commission (MRC) (2017b). The Council Study: Study on the Sustainable Management and Development of the Mekong River, Including Impacts of Mainstream Hydropower Projects. Cumulative Impact Assessment Key Findings Report. Draft Report. Vientiane, Lao PDR.

Meynell, P., Carew-Reid, J., Räsänen, T., Tilleard, S., and Ketelsen, T. (2014). Exploring Environmental Flows: Case Study of the Lower Se San River. Project Report: Challenge Program on Water \& Food Mekong project MK3 "Optimizing the Management of a Cascade of Reservoirs at the Catchment Level". Hanoi: ICEM-International Centre for Environmental Management.

Meynell, P.-J. (2013). Conclusions and Recommendations from the MK3 Project. Project report: Challenge Program on Water \& Food Mekong project MK3 "Optimizing the Management of a Cascade of Reservoirs at the Catchment level". Hanoi: ICEM-International Centre for Environmental Management.

Mitchell, J. (1997). Mitigation in environmental assessment-furthering best practice. Environ. Assess. 5, 28-29.

Mthethwa, N. (2016). Angola’s hydropower projects pose potential environmental risks. African Mining Brief. (Accessed November 08, 2016).

NCEA Netherlands Commission for Environmental Assessment (2015). Sustainable Hydropower Development: the Role of EIA and SEA. 6. Available online at: http://api.commissiemer.nl/docs/mer/diversen/case_hydropwer_ jan_2015.pdf

OKACOM (2011a). The Permanent Okavango River Basin Water Commission: Cubango-Okavango River Basin Transboundary Diagnostic Analysis. Maun, Botswana: OKACOM. 218.

OKACOM (2011b). The Permanent Okavango River Basin Water Commission: Cubango-Okavango River Basin Strategic Action Programme (SAP) for the Sustainable Development and Management of the Cubango-Okavango Basin. Maun, Botswana: OKACOM.

Opperman, J. J., and Harrison, D. (2008). Pursuing Sustainability and Finding Profits: Integrated Planning at the System Scale. Sacramento, CA: Hydrovision, 2008; HCI Publications.

Pierce-Smith, S. W. D. (2012). The impact of continued Mekong Basin hydropower development on local livelihoods. Consilience J. Sustainable Dev. 7, 73-86.

Richter, B. D., Baumgartner, J. V., Wigington, R., and Braun, D. P. (1997). How much water does a river need? Freshwater Biol. 37, 231-249.

SLR Consulting (2017). Nenskra Hydropower Project. Supplementary Environmental and Social Studies. Vol. 10: Cumulative Impact Assessment. JSC Nenskra Hydro, 84.

United States of America Environmental Protection Agency (US EPA) (1989). Dam Water Quality Study: Report To Congress. Washington, USA.

Vörösmarty, C. J., McIntyre, P. B., Gessner, M. O., Dungeon, D., Prusevich, A., Green, P., et al. (2010). Global threats to human water security and river biodiversity. Nature 467, 555-561. doi: 10.1038/nature 09440

World Bank Group (2018). Good Practice Handbook: EFlows Assessments for Hydropower Projects. (Washington, DC: World Bank Group), 135. 
World Bank, Economic Consulting Associates and Afrika J. G. (in press). CubangoOkavango River Basin: Multi-Sectoral Opportunities Analysis. Washington, DC: World Bank.

World Commission on Dams (WCD) (2000). Dams and Development a New Framework for Decision-Making. The Report of the World Commission on Dams. London: Earthscan Publications; Thanet Press.

Zarfl, C., Lumsdon, A. E., Berlekamp, J., Tydecks, L., and Tockner, K. (2015). A global boom in hydropower dam construction. Aquat. Sci. 77, 161-170. doi: 10.1007/s00027-014-0 $377-0$
Conflict of Interest Statement: The authors declare that the research was conducted in the absence of any commercial or financial relationships that could be construed as a potential conflict of interest.

Copyright (c) 2018 King and Brown. This is an open-access article distributed under the terms of the Creative Commons Attribution License (CC BY). The use, distribution or reproduction in other forums is permitted, provided the original author(s) and the copyright owner(s) are credited and that the original publication in this journal is cited, in accordance with accepted academic practice. No use, distribution or reproduction is permitted which does not comply with these terms. 